Article

\title{
Antiradical and Antioxidative Activity of Azocalix[4]arene Derivatives: Combined Experimental and Theoretical Study
}

\author{
Jiaqi Ni ${ }^{1,2}$, Lilin Lu ${ }^{1,2, *(D)}$ and Yi Liu ${ }^{2,3}$ \\ 1 State Key Laboratory of Refractories and Metallurgy, Wuhan University of Science and Technology, \\ Wuhan 430081, China; 15671569690n@sina.com \\ 2 Hubei Province Key Laboratory of Coal Conversion and New Carbon Materials, School of \\ Chemistry and Chemical Engineering, Wuhan University of Science and Technology, Wuhan 430081, China; \\ yiliuchem@whu.edu.cn \\ 3 State Key Laboratory of Virology \& Key Laboratory of Analytical Chemistry for Biology and Medicine, \\ College of Chemistry and Molecular Science, Wuhan University, Wuhan 430072, China \\ * Correspondence: lulilin@wust.edu.cn
}

Received: 15 January 2019; Accepted: 28 January 2019; Published: 29 January 2019

\begin{abstract}
Developing antioxidants with high efficiency is fundamentally important for the protection of living cells and engineering materials against oxidative damage. In this present study, two azocalix[4]arene derivatives were synthesized via a diazo coupling reaction between calix[4]arene and diazonium salts. Their antiradical and antioxidative performances were evaluated by hydroxyl radical scavenging and pyrogallol autoxidation inhibition experiments. Combined with theoretical studies, the antiradical and antioxidative mechanisms have been explored. The results demonstrated that these two azocalix[4]arene derivatives both exhibited remarkable antiradical and antioxidative activity. The macrocyclic framework of the calix[4]arene and para-azo substituent group at the upper rim of calix[4]arene contributed synergistically and importantly to its excellent antiradical and antioxidant activity.
\end{abstract}

Keywords: azocalix[4]arene; antiradical; antioxidant; mechanism; density functional theory

\section{Introduction}

Reactive oxygen species (ROS) are widely found in a number of life-sustaining biochemical processes in living cells, such as aerobic metabolism [1]. Furthermore, these types of reactive species are involved in many material fields (e.g., polymers and lubricants) and industries (e.g., food industry). Oxidative degradation resulting from reactive species is a general phenomenon that occurs in living cells and engineering materials, leading to many severe problems, such as cardiovascular disease, cancer, chronic inflammatory diseases [2], and a sharp deterioration of the mechanical properties of engineering materials. Therefore, developing efficient antioxidants to scavenge reactive oxygen species and to alleviate oxidative damage has always been an imperative research issue for many decades.

Calixarene, which are the cyclic oligomers obtained by the condensation of formaldehyde with p-alkylphenols, has been considered to be the third generation supramolecular host molecule after crown ethers and cyclodextrins. It has been extensively used in molecular recognition, ion sensing and drug delivery [3-5]. Due to the hindered phenol molecular structure, calixarene and its derivatives were also reported to be part of a class of excellent antioxidants with inherent antioxidative activities. $p$-tertbutyl-calix[4]arene was reported to be effective light and heat stabilizers for polyolefins [6,7]. The radiation stability of polypropylene can be significantly improved by $p$-tert-butylcalix[n]arene [8]. Low density polyethylenes and high density polyethylenes could 
be effectively stabilized by $p$-tertbutyl-calix[4]arene and $p$-tertbutyl-calix[6]arene, respectively [9]. Calix[n]arenes that feature sulphonate groups above and/or below the plane of the macrocycle have intrinsic antioxidant capacity and antibacterial activity [10]. Four dihydropyrimidine moieties were grafted at the upper rim of calix[4]arene, which produced calix[4]arene-based dihydropyrimidines that possess amplified antiradical activity in comparison to the corresponding monomers [11]. Furthermore, a calix[4]arene-like tetramer of resveratrol was reported to exhibit significantly improved antioxidative activity with respect to resveratrol [12]. Calixarene-based antioxidant C-methylcalix[4]resorcinarene also exhibited superior antioxidative efficiency in natural rubber vulcanizates compared to that of classical antioxidant 2,6-di-tert-butyl-4-methylphenol (BHT) [13]. In addition, calix[4]arene has also been used for rigid molecular scaffolds to cluster hydroxycinnamic acid in order to improve radical scavenging and antioxidative activity [14].

In this work, two azocalix[4]arene derivatives (Figure 1), which were namely 5,11,17,23-tetrakis[(p-carb oxyphenyl)azo]-25,26,27,28-tetrahydroxycalix[4]arene (1) and 5,11,17,23-tetrakis[(3-pyridine)azo]-25,26,27, 28-tetra hydroxycalix[4]arene (2), were synthesized via a diazo coupling reaction between calix[4]arene and diazonium salts. It was then characterized by ${ }^{1} \mathrm{H}-\mathrm{NMR}$ and IR (Figure 2). Their antiradical capacities were evaluated by hydroxyl radical $(\cdot \mathrm{OH})$ scavenging experiments and their antioxidative activities were tested by a pyrogallol autoxidation inhibiting experiment. To elucidate the antiradical and antioxidative mechanisms, combined experimental and theoretical studies were also performed to explore the necessary pharmacophores that are responsible for their antiradical and antioxidative activities. The effect of the calix[4]arene framework and azo substituent group at the upper rim of calix[4]arene on the antiradical and antioxidative activities were experimentally investigated by comparison with calix[4]arene (3) and the corresponding monomer model compounds, $p$-carboxyphenyl-azo-phenol (4) and 3-aminopyridine-azo-phenol (5). The antiradical and antioxidative mechanisms were theoretically studied on the basis of hydrogen abstraction transfer (HAT) and sequential proton loss electron transfer (SPLET) pathways.

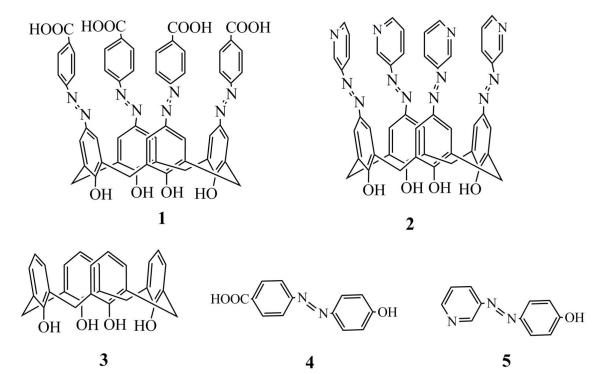

Figure 1. Chemical structures of azocalix[4]arene derivatives $\mathbf{1}$ and 2, calix[4]arene (3), p-carboxyphenyl-azo-phenol (4) and 3-aminopyridine-azo-phenol (5).

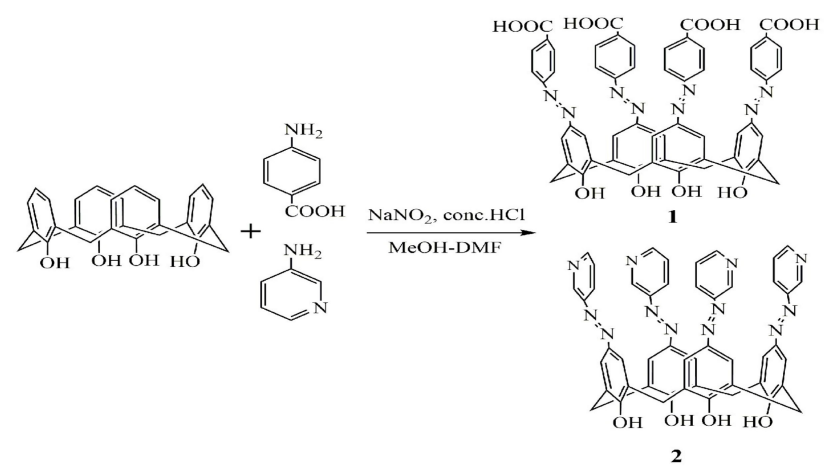

Figure 2. Synthesis route of azocalix[4]arene derivatives $\mathbf{1}$ and $\mathbf{2}$. 


\section{Results and Discussion}

\subsection{Hydroxyl Radical Scavenging Activity}

In this work, hydroxyl radicals $(\cdot \mathrm{OH})$ were produced via irradiation decomposition of $\mathrm{H}_{2} \mathrm{O}_{2}$ [15,16] before being reacted with terephthalic acid to form a fluorescent compound hydroxyterephthalic acid (HTA, $\lambda_{\mathrm{em}} 425 \mathrm{~nm}$ ) $[17,18]$. The reactions are described as follows:

$$
\begin{gathered}
\mathrm{H}_{2} \mathrm{O}_{2} \stackrel{254 \mathrm{~nm} \text { UV irradiation }}{\longrightarrow} 2 \bullet \mathrm{OH} \\
\bullet \mathrm{OH}+\text { terephthalic acid }(\mathrm{TA}) \rightarrow \mathrm{HTA} \text { (fluorescent) }
\end{gathered}
$$

In the antiradical experiment, the antioxidant competes with terephthalic acid to trap hydroxyl radicals, thus inhibiting the production of HTA and leading to a decrease in fluorescence intensity. The results of hydroxyl radical scavenging of azocalixarene derivatives $\mathbf{1}$ and $\mathbf{2}$ are shown in Figure 3. As shown in Figure 3, a significant decrease in fluorescence intensity at $425 \mathrm{~nm}$ was induced by azocalixarene derivatives $\mathbf{1}$ and $\mathbf{2}$. The hydroxyl radical scavenging efficiency was calculated according to the following equation:

$$
d=\left(\mathrm{I}_{0}-\mathrm{I}_{\mathrm{f}}\right) / \mathrm{I}_{0} \times 100 \%
$$

where the $I_{0}$ and $I_{f}$ represent the fluorescence intensity before and after the addition of azocalixarene, respectively.

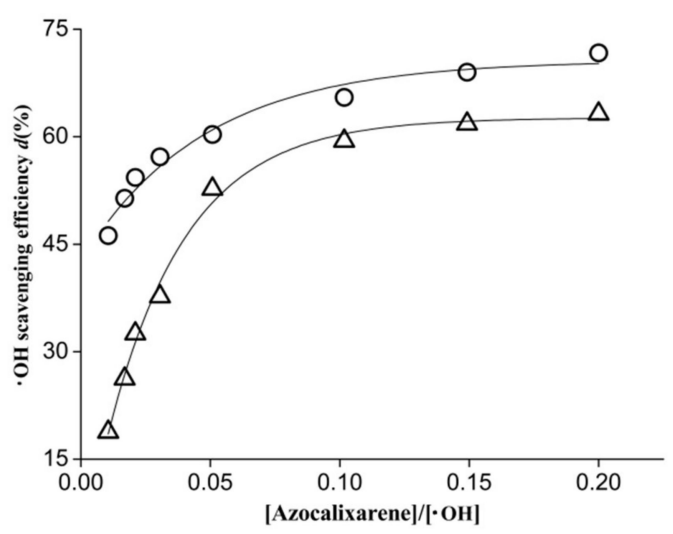

Figure 3. Hydroxyl radical scavenging efficiency as a function of the concentration ratio of [azocalixarene]/[.OH] where cycle $(\bigcirc)$ and triangle $(\triangle)$ represent azocalix[4]arene derivatives 1 and 2 , respectively.

Figure 3 shows the plot of hydroxyl radical scavenging efficiency $(d)$ against the concentration ratio of [azocalixarene]/[.OH] . At the [azocalixarene]/[. OH] ratio of 0.02 , the hydroxyl radical scavenging efficiency of $\mathbf{1}$ and 2 are approximately 54.3\% and 32.5\%, respectively. When the concentration ratio increased to approximately 0.2 , the hydroxyl radical scavenging efficiencies increased to $71.7 \%$ and $63.2 \%$, respectively. Compared with compound 2, the calix[4]arene derivative 1 showed higher hydroxyl radical scavenging activity, especially at a low concentration range. For instance, at the [azocalixarene]/[.OH] ratio of 0.01 , the hydroxyl radical scavenging efficiency of $\mathbf{1}$ is about $45 \%$, which is almost three-fold of that (approximately 15\%.) of 2, demonstrating that compound 1 possesses greater antiradical capacity than compound 2 . These results demonstrated that the two investigated azocalixarene derivatives both exhibited significant scavenging activity for hydroxyl radicals.

\subsection{Pyrogallol Autoxidation Inhibition Activity}

The autoxidation of pyrogallol in an alkaline aqueous solution has been extensively observed in previous works $[19,20]$. In this present study, pyrogallol autoxidation experiments have also been 
performed and the UV-vis absorption spectrum was constantly measured (displayed in Figure 4). An increasing absorption peak at $320 \mathrm{~nm}$ was observed and the absorbance reached its maximum after pyrogallol autoxidation for $30 \mathrm{~min}$. In this work, the pyrogallol autoxidation inhibition experiments of azocalixarene derivatives were allowed to proceed for $30 \mathrm{~min}$ before the absorbance at $320 \mathrm{~nm}$ was measured to calculate the inhibition efficiency $E(\%)$ according to the following equation:

$$
E \%=\frac{A_{0}-A}{A_{0}} \times 100 \%
$$

where $A_{0}$ was the absorbance at $320 \mathrm{~nm}$ after autoxidation for $30 \mathrm{~min}$ when no antioxidant was added and $A$ was the absorbance after azocalixarene was added as an antioxidant.

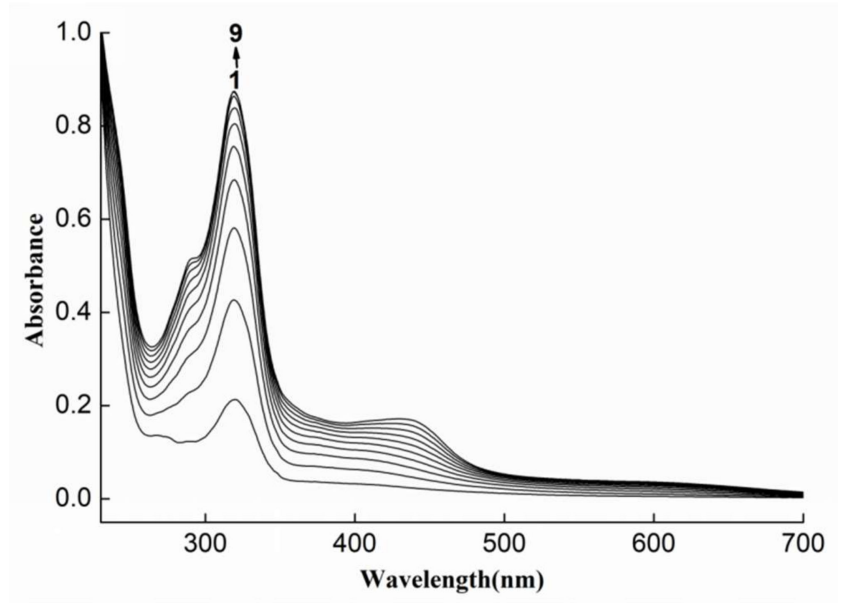

Figure 4. Absorption spectrum of pyrogallol in Tris- $\mathrm{HCl}$ buffer solution $(\mathrm{pH}=8.2)$ after autoxidation for $0.5,4.0,8.0,12.0,16.0,20.0,24.0,28.0$ and $32.0 \mathrm{~min}(1-9)$.

The performances of azocalixarene derivatives in the pyrogallol autoxidation inhibition experiment are displayed in Figure 5. As shown in Figure 5, the investigated azocalix[4]arene derivatives $\mathbf{1}$ and $\mathbf{2}$ both exhibited remarkable activity in pyrogallol autoxidation inhibition. When [azocalixarene]/[pyrogallol] ratio was equal to 0.01 , the inhibition efficiencies reach about $25 \%$ and $18 \%$ for $\mathbf{1}$ and 2 , respectively. With an increase in the concentration ratio of [azocalixarene]/[pyrogallol], the inhibition efficiency increases correspondingly. When the concentration ratio increased to 0.07 , the inhibition efficiency increased to $36.9 \%$ and $31.8 \%$, respectively, for $\mathbf{1}$ and 2. Similarly, compound $\mathbf{1}$ exhibited higher activity in the inhibition of pyrogallol autoxidation compared to compound 2 over the whole testing range of [azocalixarene]/[pyrogallol] ratios, indicating that the azocalixarene derivatives 1 possess more excellent antioxidative capacity.

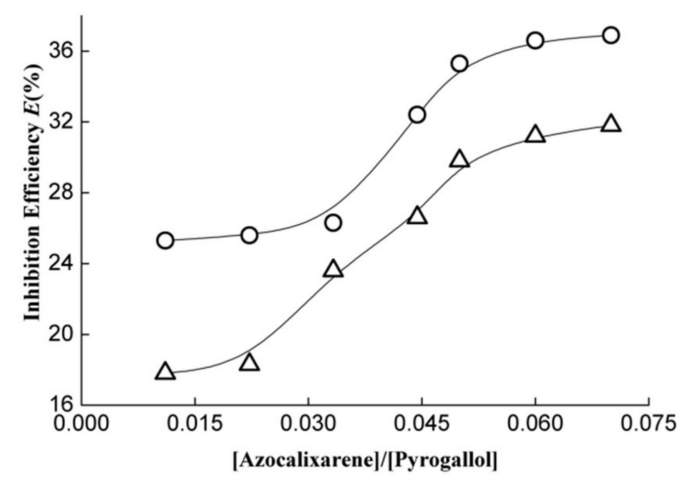

Figure 5. Pyrogallol autoxidation inhibition efficiency as a function of the concentration ratio of [azocalixarene]/[pyrogallol] where cycle $(\bigcirc)$ and triangle $(\triangle)$ represent azocalix[4]arene derivatives 1 and 2 , respectively. 
The performance of calix[4]arene (3), p-carboxyphenyl-azo-phenol (4) and 3-aminopyridine-azophenol (5) in hydroxyl radical scavenging and pyrogallol autoxidation inhibition experiments were also investigated and compared to each other. An [antioxidant]/[-OH] ratio of 0.1 and [antioxidant]/[pyrogallol] of 0.05 were selected, respectively, for hydroxyl radical scavenging and pyrogallol autoxidation inhibition experiments under identical experimental conditions. The results manifested that calix[4]arene, $p$-carboxyphenyl-azo-phenol and 3-aminopyridine-azo-phenol exhibited negligible antiradical capacity and antioxidative activity. The hydroxyl radical scavenging efficiencies of calix[4]arene, $p$-carboxyphenyl-azo-phenol and 3-aminopyridine-azo-phenol were $2.8 \%, 5.2 \%$ and $3.6 \%$, respectively. In pyrogallol autoxidation inhibition experiments, the inhibition efficiencies of these compounds were $1.9 \%, 1.6 \%$ and $1.4 \%$, respectively. These results demonstrated that the macrocyclic framework of calix[4]arene or azo group was not the crucial factor that is individually responsible for determining the capacity of azocalix[4]arene derivatives. It was the synergistic effect of the macrocyclic framework of calix[4]arene and azo group at the upper rim of calix[4]arene that might result in the significant antiradical and antioxidative activity of azocalixarene derivatives $\mathbf{1}$ and $\mathbf{2}$.

\subsection{Phenolic $\mathrm{O}-\mathrm{H} B D E s$, Proton Affinities (PAs) and Electron Transfer Enthalpies of Phenolate Anions}

For phenolic antioxidants, their radical scavenging and antioxidative activity rely significantly on their ability to transfer their phenolic $\mathrm{H}$-atom to radical species in order to break the chain reaction. Generally, there are two pathways for $\mathrm{H}$-atom transfer, which are namely the hydrogen abstraction transfer (HAT) and sequential proton loss electron transfer (SPLET) [21,22]. In the former case, the antioxidant donates a $\mathrm{H}$-atom via the homolytic dissociation of the phenolic $\mathrm{O}-\mathrm{H}$ bond, which is under the control of the O-H bond dissociation enthalpy (BDE). The lower O-H BDE has a weaker phenolic $\mathrm{O}-\mathrm{H}$ bond and favors the $\mathrm{O}-\mathrm{H}$ homolytic dissociation donating the $\mathrm{H}$-atom. In the latter case, the $\mathrm{H}$-atom transfer process is governed by the acidity of phenolic $\mathrm{O}-\mathrm{H}$, which is generally characterized by the proton affinity (PA) of the corresponding phenolate anion. A lower PA means the stronger $\mathrm{O}-\mathrm{H}$ acidity, which is more favorable for the heterolytic dissociation. Compared with a neutral molecule, the produced phenolate anion has the lower ionization potential, which facilitates the sequential electron transfer process to produce the phenoxyl radical.

Considerable efforts have been devoted to the measurement of $\mathrm{O}-\mathrm{H}$ BDE using versatile techniques, such as photoacoustic calorimetry [23] and EPR spectroscopy [24,25]. Quantum mechanical methods have also been extensively used for evaluating the O-H BDE [26,27]. In this present work, DFT calculations have been performed at the BP86/6-311+G(d,p) level of theory to calculate the O-H BDEs and the PAs of phenolate anions of azocalixarene derivatives $\mathbf{1}$ and $\mathbf{2}$ in an aqueous solution in order to explore the antiradical and antioxidative mechanisms [12,28]. For comparison, the $\mathrm{O}-\mathrm{H}$ BDEs of calix[4]arene, $p$-carboxyphenyl-azo-phenol and 3-aminopyridine-azo-phenol and the PAs of phenolate anions of them are also calculated. All of the results are listed in Table 1.

Table 1. The calculated phenolic O-H bond dissociation enthalpies (BDEs) and proton affinities (PAs) of phenolate anions of investigated chemical systems at BP86/6-311+G(d,p) level of theory.

\begin{tabular}{cccc}
\hline \multirow{2}{*}{ Compounds } & \multirow{2}{*}{ O-H BDEs (kcal/mol) } & \multicolumn{2}{c}{ Phenolate Anion } \\
\cline { 3 - 4 } & & PAs (kcal/mol) & ETEs (kcal/mol) \\
\hline Calix[4]arene & $82.17^{*}$ & 276.59 & 117.74 \\
p-carboxyphenyl-azo-phenol & 81.26 & 278.57 & 115.21 \\
3-aminopyridine-azo-phenol & 81.42 & 279.54 & 114.41 \\
$\mathbf{1}$ & $76.39^{*}$ & 265.85 & 122.89 \\
$\mathbf{2}$ & $77.97^{*}$ & 266.70 & 123.64 \\
\hline
\end{tabular}

* For calix[4]arene compounds, only one phenolic hydroxyl was arbitrarily selected to be studied by DFT calculations.

As shown in Table 1, the calculated O-H BDE of calix[4]arene, $p$-carboxyphenyl-azo-phenol and 3-aminopyridine-azo-phenol is $82.17,81.26$ and $81.42 \mathrm{kcal} / \mathrm{mol}$, respectively. In azocalix[4]arene derivatives $\mathbf{1}$ and 2, the O-H BDEs were 76.39 and $77.97 \mathrm{kcal} / \mathrm{mol}$, respectively. They are distinctly 
lower than those of calix[4]arene, p-carboxyphenyl-azo-phenol and 3-aminopyridine-azo-phenol. This indicated that the phenolic $\mathrm{O}-\mathrm{H}$ bonds in azocalix[4]arene derivatives $\mathbf{1}$ and $\mathbf{2}$ were significantly weakened, thus facilitating $\mathrm{H}$-atom being donated from the phenolic $\mathrm{O}-\mathrm{H}$ group to break the chain reaction of radicals. This result is consistent with the above-mentioned experimental findings that azocalix[4]arene derivatives showed superior hydroxyl radical scavenging capacity compared to calix[4]arene, $p$-carboxyphenyl-azo-phenol and 3-aminopyridine-azo-phenol.

The proton affinities and electron transfer enthalpy of phenolate anions were also investigated to explore the acidity of phenolic $\mathrm{O}-\mathrm{H}$ and electron loss capacity of phenolate anions. For phenolate anions of all investigated compounds, the calculated electron transfer enthalpy is significantly lower than the proton affinity, indicating that the first proton dissociation is the rate-determined step of the sequential proton loss electron transfer (SPLET) process. For calix[4]arene, $p$-carboxyphenyl-azo-phenol and 3-aminopyridine-azo-phenol, their proton affinities were calculated to be 276.59, 278.57 and $279.54 \mathrm{kcal} / \mathrm{mol}$, respectively. The calculated proton affinities of azocalix[4]arene derivatives $\mathbf{1}$ and $\mathbf{2}$ are $265.85 \mathrm{kcal} / \mathrm{mol}$ and $266.70 \mathrm{kcal} / \mathrm{mol}$, respectively. The distinct decrease in the proton affinity of azocalix[4]arene derivatives with respect to those of calix[4]arene, $p$-carboxyphenyl-azo-phenol and 3-aminopyridine-azo-phenol indicated the stronger acidity of the $\mathrm{O}-\mathrm{H}$ group, which would facilitate the production of phenolate anions.

As concluded from the above-mentioned results, the synergistic effect of macrocyclic framework of calix[4]arene and azo group at the upper rim of calix[4]arene is responsible for the lower O-H BDEs and proton affinity of the phenolate anion, thus resulting in the excellent radical scavenging activity and pyrogallol autoxidation inhibition ability of azocalix[4]arene derivatives $\mathbf{1}$ and $\mathbf{2}$.

In previous works, the superoxide anion radical $\left(\cdot \mathrm{O}_{2}{ }^{-}\right)$has been confirmed to be involved in the autoxidation of pyrogallol [29] and inhibition of pyrogallol autoxidation was widely used to measure the capacity of antioxidants to scavenge superoxide anion radicals [20]. In this work, the investigated azocalixarene derivatives exhibited excellent activity for pyrogallol autoxidation inhibition, which might be explained by the strong acidity of their O-H group. Firstly, the negatively charged superoxide anion radical, which was produced during pyrogallol autoxidation, accepted the proton donated by azocalix[4]arene derivatives to form a neutral radical $\cdot \mathrm{O}_{2} \mathrm{H}$. Secondly, the electron was transferred from the phenolate anion of the azocalixarene derivative to $\cdot \mathrm{O}_{2} \mathrm{H}$ and subsequently quenched the anion. As shown by the relatively higher PA of phenolate anion with respect to O-H BDE in Table 1, the investigated azocalix[4] arene derivatives possess more excellent activity in hydroxyl radical scavenging than in superoxide anion radical scavenging, thus exerting higher efficiency in the hydroxyl radical scavenging experiment but relatively lower efficiency in the pyrogallol autoxidation inhibition experiment. This is consistent with the experimental performance as the highest efficiency of hydroxyl radical scavenging for the investigated azocalix[4]arene derivatives was about 71.7\%, whereas the highest efficiency of pyrogallol autoxidation inhibition was only about $36.9 \%$.

\subsection{Spin Density Distribution Analysis of Phenoxyl Radicals}

The stability of the phenoxyl radical produced via the HAT or SPLET process is another important index for antioxidants. It is desirable that a phenoxyl radical is produced with enough stability because otherwise it may not be able to easily induce a new chain reaction between itself and substrates. The unpaired electron distribution in phenoxyl radical plays an important role in determining its stability. More delocalized unpaired electrons in the radical creates more stability in the radical. In this present study, a spin density distribution analysis was performed and displayed in Figure 6 to explore the unpaired electron delocalization in the phenoxyl radical of azocalix[4]arene derivatives. Furthermore, the phenoxyl radicals of calix[4]arene, p-carboxyphenyl-azo-phenol and 3-aminopyridine-azo-phenol were also investigated and compared. 


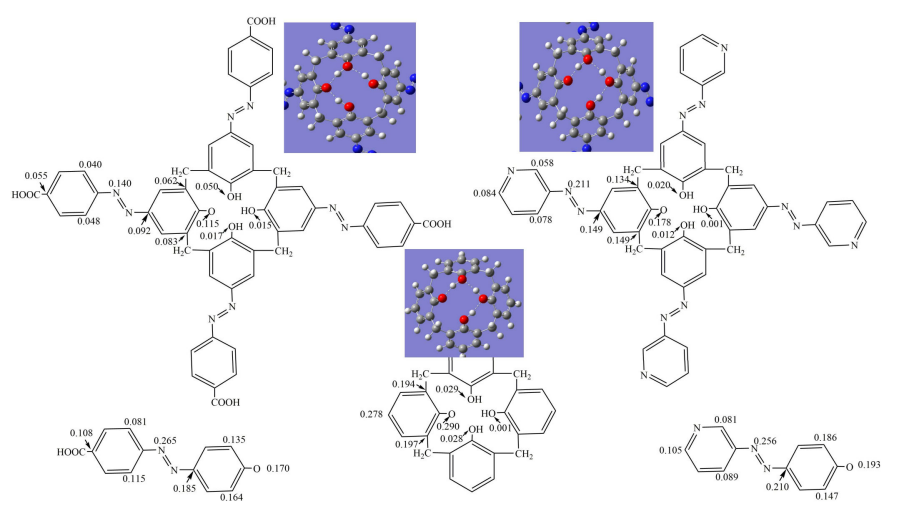

Figure 6. Spin density distribution in the phenoxyl radicals of azocalix[4]arene derivatives $\mathbf{1}$ and 2, calix[4]arene, $p$-carboxyphenyl-azo-phenol and 3-aminopyridine-azo-phenol.

As shown in Figure 6, in the phenoxyl radicals of p-carboxyphenyl-azo-phenol and 3-aminopyridine-azo-phenol, the unpaired electron is mainly confined to the remaining phenolic oxygen atom, carbon atom in benzene ring and the nitrogen atom in the azo group. The spin density on the phenolic O-atom are 0.170 and 0.193 , respectively. In the phenoxyl radical of calix[4]arene, the unpaired electron was confined to the remaining phenolic O-atom and the connected phenol ring, which results in the spin density of 0.290 on the remaining phenolic O-atom. In phenoxyl radicals of azocalix[4]arene derivatives $\mathbf{1}$ and $\mathbf{2}$, the spin density on the remaining phenolic O-atom decreased to 0.115 and 0.178 , respectively. These values are significantly lower than the corresponding spin density in the phenoxyl radicals of calix[4]arene, $p$-carboxyphenyl-azo-phenol and 3-aminopyridine-azo-phenol. These results demonstrated that the unpaired electron in phenoxyl radicals is more delocalized while the macrocyclic framework of calix[4]arene and azo substituent group at the upper rim of calixarene contributed synergistically and importantly to the delocalization of unpaired electrons.

\section{Materials and Methods}

3.1. Synthesis of 5,11,17,23-tetrakis[(p-carboxyphenyl)azo]-25,26,27,28-tetrahydroxycalix[4]arene (1) and 5,11,17,23-tetrakis[(3-pyridine) azo]-25,26,27,28-tetrahydroxycalix[4]arene (2)

$p$-tert-butylcalix[4]arene was synthesized according to the method described in literature [30]. Calix[4]arene was prepared by the debutylation of $p$-tertbutylcalix[4]arene [31]. The azocalix[4]arene derivatives ( $\mathbf{1}$ and 2$)$ were synthesized via a diazo coupling reaction between calix[4]arene and diazonium salts [32-34].

In a typical synthesis, $0.685 \mathrm{~g}$ of $p$-aminobenzoic acid crystal was added to $10 \mathrm{~mL}$ of water while constantly stirring and heating. After it was dissolved, the solution was cooled down to $5{ }^{\circ} \mathrm{C}$ in an ice bath before a solution of $0.345 \mathrm{~g} \mathrm{NaNO}_{2}$ dissolved in $2.5 \mathrm{~mL}$ of water was added. The solution was acidified by a diluted aqueous $\mathrm{HCl}$ solution. After half an hour of stirring, approximately $0.2 \mathrm{~g}$ of urea was added and the solution was stirred for a further $10 \mathrm{~min}$ to obtain the solution of diazonium salt. The diazonium salt solution was added into a cold solution of $1.0 \mathrm{~g}$ $(2.36 \mathrm{mmol})$ calix[4]arene and $2.46 \mathrm{~g}(30 \mathrm{mmol})$ of anhydrous sodium acetate in $26 \mathrm{~mL}$ of MeOH-DMF $(5: 8 \mathrm{v} / \mathrm{v})$ in order to produce a red suspension. This red reactant was allowed to couple for two hours in an ice bath, which was subsequently acidified by $150 \mathrm{~mL}$ of a $\mathrm{HCl}$ aqueous solution and warmed at $60{ }^{\circ} \mathrm{C}$ for $30 \mathrm{~min}$ to produce a reddish viscous solid. After being filtered out, the solid was washed with water and methanol several times before being dried under vacuum to obtain 5,11,17,23-tetrakis[( $p$-carboxyphenyl)azo]-25,26,27,28-tetrahydroxy-calix[4]arene (1). We obtained the following results. ${ }^{1} \mathrm{H}-\mathrm{NMR}(\mathrm{DMSO}-\mathrm{D}), \delta(\mathrm{ppm}): 3.8$ and $4.0\left(\mathrm{~d}, 8 \mathrm{H}, \mathrm{ArCH}_{2} \mathrm{Ar}\right), 8.0 \sim 8.1(\mathrm{~m}, 4 \mathrm{H}$, $\mathrm{ArOH}), 7.1 \sim 7.8(\mathrm{~m}, 24 \mathrm{H}, \mathrm{Ar}), 8 \sim 14(\mathrm{~s}, 4 \mathrm{H}, \mathrm{COOH}) . \mathrm{IR}, v: 3421 \mathrm{~cm}^{-1}$ and $3190 \mathrm{~cm}^{-1}(\mathrm{OH}), 1602 \mathrm{~cm}^{-1}$ $(\mathrm{N}=\mathrm{N}), 1408 \mathrm{~cm}^{-1}(\mathrm{C}=\mathrm{O} / \mathrm{ArCOOH})$. In a similar procedure, $0.77 \mathrm{~g}(10 \mathrm{mmol})$ 3-aminopyridine 
was used to synthesize 5,11,17,23-tetrakis[(3-pyridine) azo]-25,26,27,28-tetrahydroxycalix[4]arene (2). ${ }^{1} \mathrm{H}-\mathrm{NMR}(\mathrm{MeOD}), \delta(\mathrm{ppm}): 4.6$ and 4.9 (d, 8H,ArCH $\left.\mathrm{Ar}_{2} \mathrm{Ar}\right), 8.6$ (s, 4H, ArOH), 6.8 8.1 (m, 24H, Ar). IR, v: $3176 \mathrm{~cm}^{-1}(\mathrm{OH}), 1594 \mathrm{~cm}^{-1}(\mathrm{~N}=\mathrm{N}), 1676 \mathrm{~cm}^{-1}(\mathrm{Ar}), 1649 \mathrm{~cm}^{-1}$ (pyridine). For comparison, p-carboxyphenyl-azo-phenol and 3-aminopyridine-azo-phenol were also synthesized in a similar way via the diazo coupling reaction between phenol and diazonium salts. All chemicals and solvents used in this work were of analytical grade and used without further purification unless otherwise mentioned. Furthermore, doubly distilled water was used for the solution preparation.

\subsection{Hydroxyl Radical Scavenging and Pyrogallol Autoxidation Inhibition}

Hydroxyl radicals were produced via the irradiation decomposition of $\mathrm{H}_{2} \mathrm{O}_{2}$ under 254-nm UV light. The amount of hydroxyl radicals was determined on the basis of the fluorescence intensity of hydroxyterephthalic acid (HTA) [35]. The details of the procedure are provided as follows. A total of $100 \mu \mathrm{L}$ of $\mathrm{H}_{2} \mathrm{O}_{2}$ solution $(20 \mathrm{mM})$, a certain volume of azocalixarene derivatives solution $(0.02 \mathrm{mM})$ and $100 \mu \mathrm{L}$ of terephthalic acid (TA) solution $(2 \mathrm{mM})$ were mixed before the final volume of mixed solution was adjusted to $5 \mathrm{~mL}$. After stirring for thirty seconds, the solution was transferred into a 1-cm quartz cell and irradiated directly under 254-nm UV light for $20 \mathrm{~min}$ at room temperature and the fluorescence intensity $\left(\lambda_{\text {ex }} 312 \mathrm{~nm}\right)$ at $425 \mathrm{~nm}$ was measured immediately. The pyrogallol autoxidation inhibition performances of the investigated samples were tested according to the following procedure. We mixed $0.3 \mathrm{~mL}$ of a pyrogallol aqueous solution $(3 \mathrm{mM}), 4.5 \mathrm{~mL}$ of a Tris- $\mathrm{HCl}$ buffer solution $(50 \mathrm{mM}$, $\mathrm{pH}=8.2)$ and a certain volume of azocalixarene derivatives solution $(0.02 \mathrm{mM})$ before the final volume was adjusted to $9 \mathrm{~mL}$. After being kept in a water bath at $25^{\circ} \mathrm{C}$ for $30 \mathrm{~min}$, the absorbance at $320 \mathrm{~nm}$ was measured. In control experiments, the azocalixarene derivatives have been replaced by other compounds, such as calix[4]arene, p-carboxyphenyl-azophenol and 3-pyridine-azophenol.

\subsection{Density Functional Theory Study of the Antiradical and Antioxidative Mechanism}

Geometries of azocalixarene derivatives ( $\mathbf{1}$ and $\mathbf{2})$, related phenoxyl radicals and phenolate anions were optimized by employing a generalized gradient approximation using the BP86 functional [36,37] and 6-31G(d) basis set. Unrestricted formulation was applied for open-shell radical species. The energies of all investigated chemical systems were refined by performing single-point calculations at BP86/6-311+G(d,p) level of theory in an aqueous solution. A polarizable continuum model (PCM) was used to simulate the aqueous solution environment with the dielectric constant of 78.3553. The antioxidative and antiradical activities of azocalixarene derivatives were theoretically studied based on the hydrogen abstraction transfer (HAT) mechanism and sequential proton loss electron transfer (SPLET) mechanism. Zero-point corrected energies and enthalpies were selected to calculate the $\mathrm{O}-\mathrm{H}$ bond dissociation enthalpy (BDE), the proton affinity (PA) and electron transfer enthalpy (ETE) of phenolate anions according to the method described in previous works [21,22]. All computations in this work are performed with the Gaussian 09W suite of programs (Gaussian, Inc., Pittsburgh, PA, USA) [38].

\section{Conclusions}

In conclusion, azocalix[4]arene derivatives $\mathbf{1}$ and $\mathbf{2}$ have been synthesized via the diazo coupling reaction between calix[4]arene and diazonium salts. Hydroxyl radical scavenging and pyrogallol autoxidation inhibition experiments demonstrated that the two investigated azocalix[4]arene derivatives both exhibited remarkable antiradical and antioxidative activity. The compound 1 showed higher activity in hydroxyl radical scavenging and pyrogallol autoxidation inhibition, with the highest hydroxyl radical scavenging efficiency and pyrogallol autoxidation inhibition efficiency found to be about $71.7 \%$ and $36.9 \%$, respectively. Combined experimental and theoretical studies revealed that the macrocyclic framework of calix[4]arene and para-azo substituent group at the upper rim of calix[4]arene mainly contributed to their antiradical and antioxidant activity due to the poor antiradical and antioxidative performance of calix[4]arene, $p$-carboxyphenyl-azo-phenol and 
3-aminopyridine-azo-phenol. DFT calculations at BP86/6-311+G(d,p) level of theory demonstrated that phenolic $\mathrm{O}-\mathrm{H}$ BDEs and proton affinities of phenolate anions of azocalix[4]arene derivatives 1 and 2 were significantly lower than that in calix[4]arene, $p$-carboxyphenyl-azo-phenol and 3-aminopyridine-azo-phenol. Spin density analysis revealed that the spin density on the remaining phenolic O-atom in the phenoxyl radicals of azocalix[4]arene derivatives $\mathbf{1}$ and $\mathbf{2}$ was distinctly lower than those in calix[4]arene, $p$-carboxyphenyl-azo-phenol and 3-aminopyridine-azo-phenol. This was indicative of a higher degree of unpaired electron delocalization and more stable phenoxyl radicals in the phenoxyl radicals of azocalix[4]arene derivatives $\mathbf{1}$ and $\mathbf{2}$. These results confirmed that the synergetic effect of macrocyclic framework of calix[4]arene and para-azo substituent group at the upper rim of calix[4]arene was responsible for the excellent antiradical and antioxidative activity of the investigated azocalix[4]arene derivatives. Thus, these derivatives would be a promising antioxidant candidate to protect living cells and engineering materials against radical and oxidative damage.

Author Contributions: Conceptualization, L.L.; Data curation, L.L.; Formal analysis, J.N., L.L. and Y.L.; Funding acquisition, L.L.; Investigation, J.N. and L.L.; Methodology, J.N. and Y.L.; Project administration, L.L.; Supervision, L.L.; Validation, Y.L.; Writing-original draft, J.N.; Writing-review \& editing, L.L. and Y.L.

Funding: This research was funded by National Natural Science Foundation of China [21671154, U1732147] and Natural Science Foundation of Hubei Province [2015CFC840].

Conflicts of Interest: The authors declare no conflict of interest. The funders had no role in the design of the study; in the collection, analyses, or interpretation of data; in the writing of the manuscript and in the decision to publish the results.

\section{References}

1. Mathews, C.K.; van Holde, K.E.; Ahern, K.G. Biochemistry, 3rd ed.; Part IV; Benjamin Cummings: San Francisco, CA, USA, 2001.

2. Valko, M.; Leibfritz, D.; Moncol, J.; Cronin, M.T.D.; Mazur, M.; Telser, J. Free radicals and antioxidants in normal physiological functions and human disease. Int. J. Biochem. Cell Biol. 2007, 39, 44-84. [CrossRef] [PubMed]

3. Ikeda, A.; Shinkai, S. Novel Cavity Design Using Calix[n]arene Skeletons: Toward Molecular Recognition and Metal Binding. Chem. Rev. 1997, 97, 1713-1734. [CrossRef] [PubMed]

4. Mokhtari, B.; Pourabdollah, K.; Dalali, N. Analytical applications of calixarenes from 2005 up-to-date. J. Incl. Phenom. Macrocycl. Chem. 2011, 69, 1-55. [CrossRef]

5. Pur, F.N. Calixdrugs: Calixarene-based cluster of established therapeutic drug agents. Mol. Divers. 2016, $20,781-787$. [CrossRef]

6. Seiffarth, K.; Schulz, M.; Gormar, G.; Bachmann, J. Calix[n]arenes-New light stabilizers for polyolefins. Polym. Degrad. Stab. 1989, 24, 73-80. [CrossRef]

7. Chennakesavulu, K.; Sreedevi, P.; Basaria, M.R.; Reddy, G.R.; Sasipraba, T.; Raju, G.B.; Prabhakar, S. Thermal decomposition mechanism of $p$-tert-butyl-calix[n]arenes. Thermochim. Acta 2014, 575, 55-63. [CrossRef]

8. Feng, W.; Yuan, L.; Zheng, S.; Huang, G.; Qiao, J.; Zhou, Y. The effect of p-tert-butylcalix[n]arene on $\gamma$-radiation degradation of polypropylene. Radiat. Phys. Chem. 2000, 57, 425-429. [CrossRef]

9. Jipa, S.; Zaharescu, T.; Setnescu, R.; Setnescu, T.; Dumitru, M.; Gorghiu, L.M.; Mihalcea, I.; Bumbac, M. Effect of calixarenes on thermal stability of polyethylenes. Polym. Degrad. Stab. 2003, 80, 203-208. [CrossRef]

10. Stephens, E.K.; Tauran, Y.; Coleman, A.W.; Fitzgerald, M. Structural requirements for anti-oxidant activity of calix[n]arenes and their associated anti-bacterial activity. Chem. Commun. 2015, 51, 851-854. [CrossRef]

11. Pur, F.N.; Dilmaghani, K.A. New Antiradical Clusters Synthesized Using the First Green Biginelli Reactions of Calix[4]Arene. Pharm. Chem. J. 2016, 50, 80-82. [CrossRef]

12. Lu, L.; Ruan, Z.; Ni, J.; Chen, J.; Shu, H.; Wang, Y.; Liu, Y. Improvement of antioxidative activity of resveratrol by calix[4]arene-like tetramer: A theoretical study. Comput. Theor. Chem. 2019, 1148, 1-7. [CrossRef]

13. Li, H.; Zhong, Y.; Wu, W.; Zhang, L.; Lai, X.; Zeng, X. Phenolic antioxidants based on calixarene: Synthesis, structural characterization and antioxidative properties in natural rubber. J. Appl. Polym. Sci. 2017, 134, 45144. [CrossRef] 
14. Consoli, G.M.L.; Galante, E.; Daquino, C.; Granata, G.; Cunsolo, F.; Geraci, C. Hydroxycinnamic acid clustered by a calixarene platform: Radical scavenging and antioxidant activity. Tetrahedron Lett. 2006, 47, 6611-6614. [CrossRef]

15. Baxendale, J.H.; Wilson, J.A. The photolysis of hydrogen peroxide at high light intensities. Trans. Faraday Soc. 1957, 53, 344-356. [CrossRef]

16. Chenna, M.; Messaoudi, K.; Drouiche, N.; Lounici, H. Study and modeling of the organophosphorus compound degradation by photolysis of hydrogen peroxide in aqueous media by using experimental response surface design. J. Ind. Eng. Chem. 2016, 33, 307-315. [CrossRef]

17. Šnyrychová, I.; Hideg, E. The first application of terephthalate fluorescence for highly selective detection of hydroxyl radicals in thylakoid membranes. Funct. Plant Biol. 2007, 34, 1105-1111. [CrossRef]

18. Zhao, J.; Dong, W.; Zhang, X.; Chai, H.; Huang, Y. FeNPs@ $\mathrm{Co}_{3} \mathrm{O}_{4}$ hollow nanocages hybrids as effective peroxidase mimics for glucose biosensing. Sens. Actuators B Chem. 2018, 263, 575-584. [CrossRef]

19. Siegel, S.M.; Siegel, B.Z. Autoxidation of Pyrogallol: General Characteristics and Inhibition by Catalase. Nature 1958, 181, 1153-1154. [CrossRef]

20. Li, X. Improved Pyrogallol Autoxidation Method: A Reliable and Cheap Superoxide-Scavenging Assay Suitable for All Antioxidants. J. Agric. Food Chem. 2012, 60, 6418-6424. [CrossRef]

21. Lu, L.; Zhu, S.; Zhang, H.; Li, F.; Zhang, S. Theoretical study of complexation of resveratrol with cyclodextrins and cucurbiturils: Structure and antioxidative activity. RSC Adv. 2015, 5, 14114-14122. [CrossRef]

22. Lu, L.; Zhu, S.; Zhang, H.; Zhang, S. Improvement of antioxidative activity of resveratrol by elongating conjugated chain: A DFT theoretical study. Comput. Theor. Chem. 2013, 1019, 39-47. [CrossRef]

23. Wayner, D.D.M.; Lusztyk, E.; Page, D.; Ingold, K.U.; Mulder, P.; Laarhoven, L.J.J.; Aldrich, H.S. Effects of Solvation on the Enthalpies of Reaction of tert-Butoxyl Radicals with Phenol and on the Calculated O-H Bond Strength in Phenol. J. Am. Chem. Soc. 1995, 117, 8737-8744. [CrossRef]

24. Lucarini, M.; Pedrielli, P.; Pedulli, G.F.; Cabiddu, S.; Fattuoni, C. Bond Dissociation Energies of O-H Bonds in Substituted Phenols from Equilibration Studies. J. Org. Chem. 1996, 61, 9259-9263. [CrossRef]

25. Lucarini, M.; Pedulli, G.F.; Cipollone, M. Bond Dissociation Enthalpy of.alpha.-Tocopherol and Other Phenolic Antioxidants. J. Org. Chem. 1994, 59, 5063-5070. [CrossRef]

26. Wright, J.S.; Carpenter, D.J.; McKay, D.J.; Ingold, K.U. Theoretical Calculation of Substituent Effects on the O-H Bond Strength of Phenolic Antioxidants Related to Vitamin E. J. Am. Chem. Soc. 1997, 119, 4245-4252. [CrossRef]

27. Kosinova, P.; Meo, F.D.; Anouar, E.H.; Duroux, J.L.; Trouillas, P. H-atom acceptor capacity of free radicals used in antioxidant measurements. Int. J. Quantum Chem. 2011, 111, 1131-1142. [CrossRef]

28. Borgohain, R.; Guha, A.K.; Pratihar, S.; Handique, J.G. Antioxidant activity of some phenolic aldehydes and their diimine derivatives: A DFT study. Comput. Theor. Chem. 2015, 1060, 17-23. [CrossRef]

29. Marklund, S.; Marklund, G. Involvement of the Superoxide Anion Radical in the Autoxidation of Pyrogallol and a Convenient Assay for Superoxide Dismutase. Eur. J. Biochem. 1974, 47, 469-474. [CrossRef]

30. Gutsche, C.D.; Iqbal, M.; Stewart, D. Calixarenes. 19. Syntheses procedures for p-tert-butylcalix[4]arene. J. Org. Chem. 1986, 51, 742-745. [CrossRef]

31. Gutsche, C.D.; Lin, L.G. Calixarenes 12: The synthesis of functionalized calixarenes. Tetrahedron 1986, 42, $1633-1640$. [CrossRef]

32. Morita, Y.; Agawa, T.; Nomura, E.; Taniguchi, H. Syntheses and NMR behavior of calix[4]quinone and calix[4]hydroquinone. J. Org. Chem. 1992, 57, 3658-3662. [CrossRef]

33. Xing, B.; Choi, M.; Zhou, Z.; Xu, B. Spontaneous Enrichment of Organic Molecules from Aqueous and Gas Phases into a Stable Metallogel. Langmuir 2002, 18, 9654-9658. [CrossRef]

34. Lu, L.; Zhu, S.; Liu, X.; Xie, Z.; Yan, X. Highly selective chromogenic ionophores for the recognition of chromium(III) based on a water-soluble azocalixarene derivative. Anal. Chim. Acta 2005, 535, 183-187. [CrossRef]

35. Armstrong, W.A.; Facey, R.A.; Grant, D.W.; Humphreys, W.D. A tissue-equivalent chemical dosimeter sensitive to $1 \mathrm{rad}$. Can. J. Chem. 1963, 41, 1575-1577. [CrossRef]

36. Becke, A.D. Density-functional exchange-energy approximation with correct asymptotic behavior. Phys. Rev. A 1988, 38, 3098-3100. [CrossRef] 
37. Perdew, J.P. Density-functional approximation for the correlation energy of the inhomogeneous electron gas. Phys. Rev. B 1986, 33, 8822-8824. [CrossRef]

38. Frisch, M.J.; Trucks, G.W.; Schlegel, H.B.; Scuseria, G.E.; Robb, M.A.; Cheeseman, J.R.; Scalmani, G.; Barone, V.; Mennucci, B.; Petersson, G.A.; et al. Gaussian 09; Revision B.02; Gaussian, Inc.: Pittsburgh, PA, USA, 2009.

Sample Availability: Samples of the compounds are available from the authors.

(C) 2019 by the authors. Licensee MDPI, Basel, Switzerland. This article is an open access article distributed under the terms and conditions of the Creative Commons Attribution (CC BY) license (http:/ / creativecommons.org/licenses/by/4.0/). 